\title{
Needs Assessment of the Undergraduate Medical Students to Incorporate Courses on Medical Education into the Undergraduate Curriculum at the Faculty of Medicine, Suez Canal University
}

Enas Mohamed Gouda ${ }^{1 *}$, Wagdy Talaat Youssef ${ }^{1}$, Adel Morshedy Hamam ${ }^{2}$ and Manal Said Fawzy

${ }^{1}$ Medical Education Department, Suez Canal University, Egypt

${ }^{2}$ Orthopaedics Department, Suez Canal University, Egypt

${ }^{3}$ Department of Medical Biochemistry, Suez Canal University, Egypt

\begin{abstract}
Aim: This study aimed to incorporate courses in medical education into the undergraduate medical curriculum at the Faculty of Medicine, Suez Canal University based on students needs for better learning.

Methodology: a descriptive study was held to assess the need to incorporate medical education related courses into the undergraduate medical curriculum at the Faculty of Medicine, Suez Canal University. The study was conducted for the undergraduate medical students' year 2009/2010.

A self administered anonymous questionnaire was designed to identify students' need to incorporate Medical Education courses into the undergraduate curriculum.

Results: The majority of the studied students were in favor of studying the suggested courses especially time management, clinical communication skills and medical ethics $(85.28 \%, 84.85 \%$ and $82.25 \%$, respectively). Fifty eight percent of studied students needed to study medical education themes as integrated courses. Most of them $(72 \%)$ needed these courses to be elective one and $(70 \%)$ needed to be taught horizontally in one phase.

Conclusion: It is important for undergraduate students to acquire knowledge, skills, and attitudes concerning their learning processes and some of the principles of medical education, especially in a faculty that adopts innovative educational strategies like FOM-SCU. It showed that the students themselves were interested in receiving these principles.
\end{abstract}

Keywords: Course; Curriculum; Time management; Clinical Communication skills; Medical ethics; Group dynamics; Students' assessment; Community-oriented Medical education

\section{Introduction and Rationale}

Medical education is increasingly being acknowledged as an essential specialty in medical schools [1]. Medical education departments are established in response to increased public expectations relating to healthcare, societal trends towards increased accountability, educational developments, and increased interest in what to teach and how to educate and train doctors. The functions of a department of medical education include research, teaching, service provision and career development of the staff. The scope of its activities includes undergraduate and postgraduate education, continuing professional development, and continuing medical education [2]. Harden [3] emphasized the importance of making medical education training compulsory for medical teachers.

The health care delivery system is experiencing enormous flux. The knowledge and skills sets required of today's physicians include expertise in competency areas that have not been included in the traditional medical curricula. The undergraduate medical education in the 21 st century will include innovative curricula that are addressing the competencies that enable the medical students to gain skills required to provide high-quality care and to cope with the modern health care environment [4].

A curriculum that does not keep pace with the needs of its learners, its faculty, its institution, its resources, patients, and society does a disservice to its constituents and is likely to deteriorate or die prematurely [5]. Hence come the importance of assessment of the needs of the undergraduate medical students before incorporation of courses on medical education in their curriculum.

Over the previous 10 years, and since the inauguration of the Medical Education Department (MED) in the Faculty of Medicine (FOM), Suez Canal University (SCU), its role was clearly defined in the sectors of service and research. Regarding the sector of education, it is clearly defined in the postgraduate education. MED-SCU is now directing its efforts towards forming structured courses tailored into the undergraduate curriculum in order to equip the students with the essential skills cardinal to proceed in PBL schools and to help the students to learn how to develop the needed skills essential for a medical student and graduate in the 21st century.

\section{Subjects and Methods}

A descriptive study was conducted to assess the need to incorporate medical education related courses into the undergraduate medical

*Corresponding author: Enas Mohamed Goudam, Medical Education Department Suez Canal University, Egypt, Tel: 1207275842; E-mail: drenasgouda@yahoo.com

Received November 04, 2013; Accepted December 20, 2013; Published December 25, 2013

Citation: Gouda EM, Youssef WT, Hamam AM, Fawzy MS (2013) Needs Assessment of the Undergraduate Medical Students to Incorporate Courses on Medical Education into the Undergraduate Curriculum at the Faculty of Medicine, Suez Canal University. Intel Prop Rights 2: 109. doi:10.4172/2375-4516.1000109

Copyright: (c) 2013 Gouda EM. This is an open-access article distributed under the terms of the Creative Commons Attribution License, which permits unrestricted use, distribution, and reproduction in any medium, provided the original author and source are credited. 
Citation: Gouda EM, Youssef WT, Hamam AM, Fawzy MS (2013) Needs Assessment of the Undergraduate Medical Students to Incorporate Courses on Medical Education into the Undergraduate Curriculum at the Faculty of Medicine, Suez Canal University. Intel Prop Rights 2: 109. doi:10.4172/2375-4516.1000109

Page 2 of 4

curriculum at the Faculty of Medicine, Suez Canal University based on students' needs for better learning and better competencies.

The study was conducted at the Faculty of Medicine, Suez Canal University for the undergraduate medical students' year 2009/2010.

A stratified random sample was taken from the undergraduate medical students in all the 6 years. They were selected through a systematic random technique by using random tables. They were divided into strata according to their grade of study and each grade was represented relatively according to their total number in the whole population.

A self administered anonymous questionnaire was designed to identify students' need to incorporate Medical Education courses into the undergraduate curriculum.

\section{Results}

The maximum contribution to the study sample was from the 4th year students (24\%) and the least one was from the 1st year students (2\%) according to their total number in the whole population as shown in (Figure 1).

Frequency distribution of the studied sample according to their needs in acquiring educational experiences in different medical education courses. The majority of the studied students were in favor of studying the suggested courses especially time management, clinical communication skills and medical ethics $(85.28 \%, 84.85 \%$ and $82.25 \%$, respectively) as shown in (Table 1). Time management and medical ethics were the top priority topics for students ( $27 \%$ and $23 \%$, respectively) while group dynamics, students' assessment and community-oriented medical education were relatively the least priority topics for students $(4 \%)$ as shown in (Figure 2). According to the studied students' point of view, small group discussion was the preferred instructional method for studying the principles of PBL and group dynamics (42\% and $37 \%$ of the students, respectively). Workshops was the preferred method for studying clinical communication skills, community-oriented medical education and effective presentation skills (55\%, 35\% and $32 \%$ of the students, respectively) while lectures was the preferred method for studying the other topics as shown in (Figure 3).Fifty eight percent of studied students needed to study medical education themes as

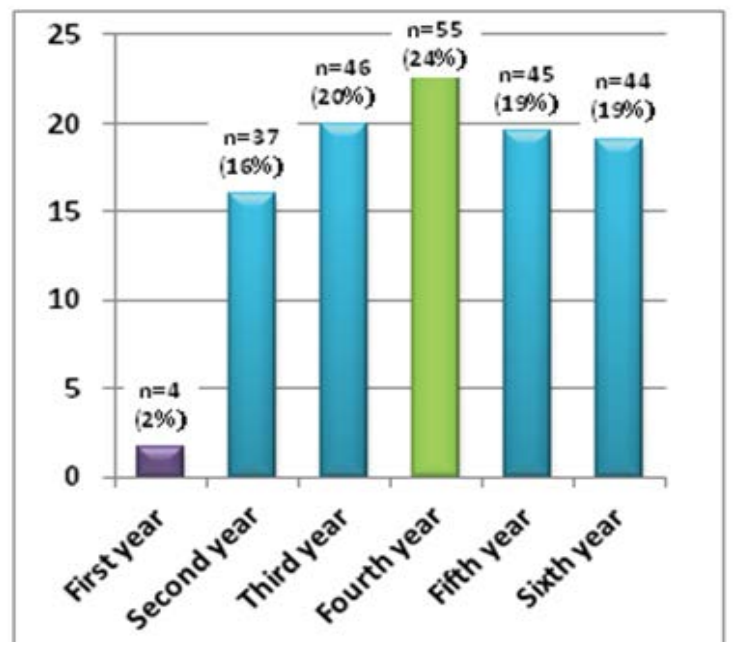

Figure 1: Frequency distribution of the studied students according to their academic year $(n=231)$

\begin{tabular}{|c|c|c|c|c|}
\hline $\begin{array}{l}\text { Opinion } \\
\text { Course }\end{array}$ & $\begin{array}{c}\text { Agree to } \\
\text { study } N(\%)\end{array}$ & $\begin{array}{c}\text { Don't agree } \\
\text { to study } N \\
(\%)\end{array}$ & $\begin{array}{c}\text { Don't know } \\
N(\%)\end{array}$ & Total N\% \\
\hline $\begin{array}{l}\text { 1.Problem Based } \\
\text { Learning }\end{array}$ & $176(76.19)$ & $49(21.22)$ & $6(2.59)$ & \multirow{9}{*}{$231(100.00)$} \\
\hline $\begin{array}{l}\text { 2. Community Oriented } \\
\text { Medical Education }\end{array}$ & $183(79.22)$ & $31(13.42)$ & $17(7.36)$ & \\
\hline $\begin{array}{l}\text { 3. Clinical } \\
\text { Communication Skills }\end{array}$ & $196(84.85)$ & $4(1.73)$ & $31(13.42)$ & \\
\hline 4. Students Assessment & $168(72.73)$ & $39(16.88)$ & $24(10.39)$ & \\
\hline $\begin{array}{l}\text { 5. Effective } \\
\text { Presentation Skills }\end{array}$ & $187(80.95)$ & $19(8.23)$ & $25(10.82)$ & \\
\hline 6. Group Dynamics & $165(71.43)$ & $32(13.85)$ & $34(14.72)$ & \\
\hline $\begin{array}{l}\text { 7. Quality and } \\
\text { Accreditation }\end{array}$ & $180(77.92)$ & $29(12.55)$ & $22(9.53)$ & \\
\hline 8. Medical Ethics & $190(82.25)$ & $31(13.42)$ & $10(4.33)$ & \\
\hline 9. Time Management & $197(85.28)$ & $13(5.63)$ & $21(9.09)$ & \\
\hline
\end{tabular}

Table 1: Frequency distribution of the studied sample according to their needs in acquiring educational experiences in different medical education courses.

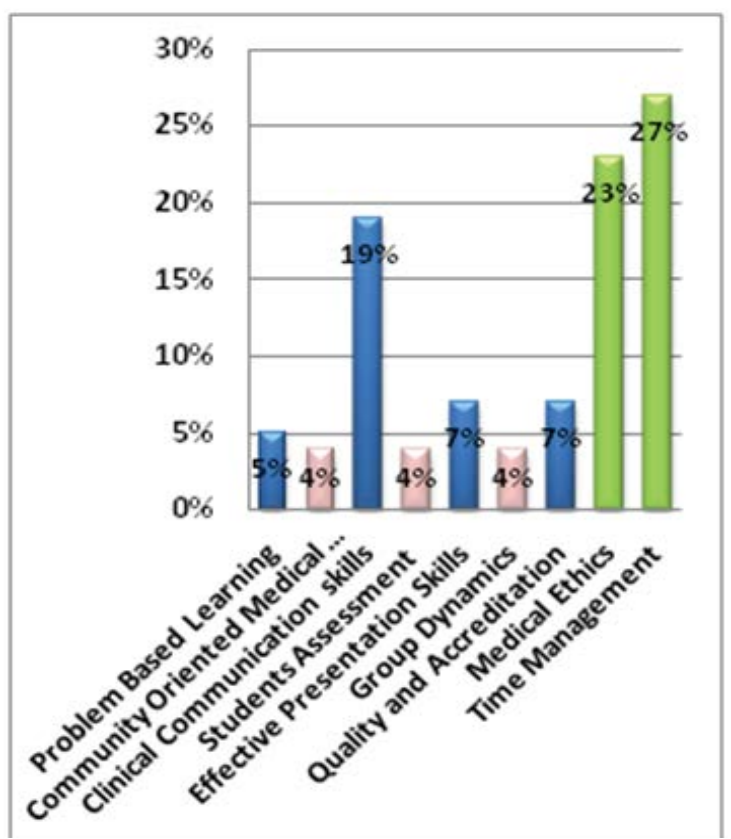

Figure 2: Percentage distribution of the studied sample according to their topic of priority in medical education.

integrated courses. Most of them (72\%) needed these courses to be elective one and (70\%) needed to be taught horizontally in one phase. High percentage of the students preferred to study all medical education courses in the first year as shown in Table 2 especially the principles of the problem based learning (Table 2).

\section{Discussion}

The overall responses of the students were positive. The majority of students were in favor of studying the suggested topics. Among the suggested topics, time management and medical ethics were rated by students as top priority ( $27 \%$ and $23 \%$, respectively) while group dynamics, students' assessment and community-oriented medical education were indicated but relatively in lower priority.

The current study revealed that (81\%) of the students were interested 
Citation: Gouda EM, Youssef WT, Hamam AM, Fawzy MS (2013) Needs Assessment of the Undergraduate Medical Students to Incorporate Courses on Medical Education into the Undergraduate Curriculum at the Faculty of Medicine, Suez Canal University. Intel Prop Rights 2: 109. doi:10.4172/2375-4516.1000109

Page 3 of 4

in studying effective presentation skills topic in the undergraduate years. This finding agreed with whittle's study [6] which emphasized that the first year medical students rated presentation skills as the most important to acquire, develop and practice during their undergraduate training. This appears to be commonsense as being able to communicate orally is important for a student's success and lack of presentation skills can derail career advancement.

Regarding the clinical communication skills topic, (85\%) of the students were interested in studying it through the undergraduate curriculum and this consistent with Sleight [7] who declared that 'Teaching communication skills is arguably the most important part of the medical curriculum, not an optional extra'. Part of the extensive change which medical education is presently undergoing is designed to place communication more conspicuously at the heart of the undergraduate medical curriculum and from the first year. In addition, these results agreed with the study conducted by the National Academy of Science to 67 medical schools. In this study, (92\%) of the total number of the medical schools selected the first year to study the communication skills. This could be explained by knowing the importance of the clinical communication skills for the medical students as it is essential for the physician to understand the patients' beliefs and cultural values. In addition, the physician must be able to teach, advice and counsel patients, families and the public about health, illness, risk factors and healthy lifestyles [8].

Most of the students (82\%) needed to acquire the educational experiences in medical ethics that is consistent with the study conducted in five Southern California medical schools which included in-depth interviews conducted with faculty members and administrators from

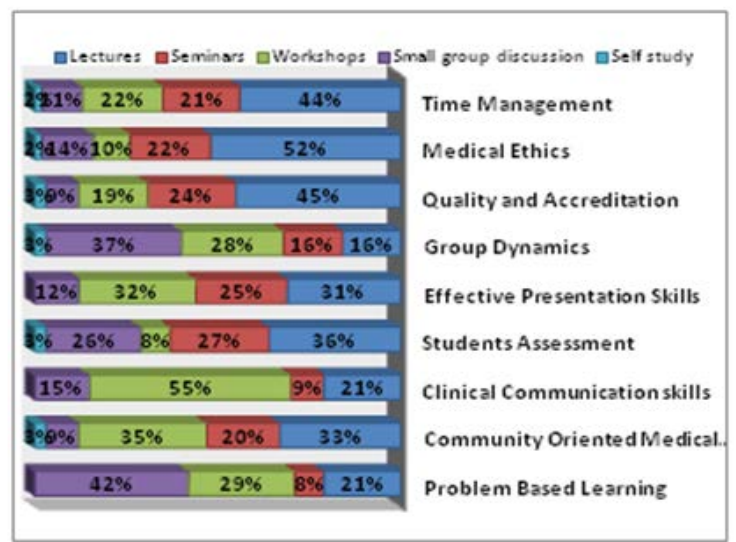

Figure 3: Frequency distribution of the studied sample according to the preferred instructional method(s) for studying medical education related courses into the undergraduate curriculum.
Loma Linda University, the University of Southern California, and the University of California at Irvine, Los Angeles, and San Diego Schools of Medicine. The researcher used a needs assessment model which leads one to conclude that the outlook for medical ethics education is necessary. This could be explained as the physicians must be prepared to meet the consequences of the rapid advances without losing the traditional values that have guided medicine for thousands of years [9].

A study conducted by the National Academy of Science in 67 medical schools revealed that about $(73 \%)$ of these schools preferred teaching medical ethics in the first year. This is consistent with the current study results as the students also preferred to study medical ethics in the first year. This agreement is due to the early contact of the medical students with the patients from the first year either in primary health care settings or in hospitals [8].

Regarding time management, it was the top priority for students in the current study and this is consistent with the study of Anderson and McClard conducted for the first year university students which pointed out the importance of teaching time management at the point of entry of the university as that will enable them to develop these skills early in the university education before poor time management and study habits are developed [10].

Most of the students were in favor of studying the suggested topics in the first year. Clinical communication skills topic was preferred to be taught by $(42 \%)$ of the students in the first year. This is in contrast with the results of the communication skills training survey which was conducted to 26 medical schools of United Kingdom universities in which 15 schools (79\%) reported that they preferred to study clinical communication skills during the third year of the undergraduate curriculum [7]. This could be explained by that FOM-SCU student's deal with the patients from the first year in the primary health care settings. Regarding the instructional methods used for teaching this topic, the current results revealed that workshop was the highest ranked method (55\%) and this also disagreed with the previous survey in which lectures was the most common used method (79\%) [7].

The current study, in addition, revealed that the students preferred lectures $(52 \%)$ as the most useful instructional method for learning medical ethics and that not consistent with the result of the study of Goldie [11] who stated that the small group discussion was viewed by students as being enjoyable and particularly well suited to medical ethics and this diversity could be explained by the difference in the study methodology as the study of Goldie is a qualitative, multi-method approach that was adopted using open questionnaires, focus groups and tutor evaluation rating scales and involved all 238 students in the first year of the medical curriculum and 30 clinical tutors on the other hand, in the current study the sample is stratified random one which was taken from the undergraduate medical students in all the 6 years included 231 students.

\begin{tabular}{|c|c|c|c|c|c|c|}
\hline $\begin{array}{l}\text { Year } \\
\text { Course }\end{array}$ & Year $1 N(\%)$ & Year $2 N(\%)$ & Year $3 N(\%)$ & Year $4 N(\%)$ & Year $5 N(\%)$ & Year $6 N(\%)$ \\
\hline 1.Problem Based Learning & $220(95.24)$ & $4(1.73)$ & $1(0.43)$ & $3(1.30)$ & $1(0.43)$ & $2(0.87)$ \\
\hline 2. Community Oriented Medical Education & $134(58.01)$ & $48(20.78)$ & $13(5.63)$ & $22(9.52)$ & $4(1.73)$ & $10(4.33)$ \\
\hline 3. Clinical Communication Skills & $98(42.41)$ & $30(12.99)$ & $34(14.72)$ & $57(24.68)$ & $6(2.60)$ & $6(2.60)$ \\
\hline 4. Students Assessment & $173(74.89)$ & $21(9.09)$ & $8(3.46)$ & $19(8.23)$ & $3(1.30)$ & $7(3.03)$ \\
\hline 5. Effective Presentation Skills & $125(54.12)$ & $28(12.12)$ & $22(9.52)$ & $27(11.69)$ & $13(5.63)$ & $16(6.92)$ \\
\hline 6. Group Dynamics & $161(69.70)$ & $21(9.09)$ & $16(6.92)$ & $18(7.79)$ & $2(0.87)$ & $13(5.63)$ \\
\hline 7. Quality and Accreditation & $112(48.49)$ & $20(8.66)$ & $22(9.52)$ & $30(12.99)$ & $12(5.19)$ & $35(15.15)$ \\
\hline 8. Medical Ethics & $111(48.05)$ & $9(3.90)$ & $11(4.76)$ & $45(19.48)$ & $7(3.03)$ & $48(20.78)$ \\
\hline 9. Time Management & $172(74.46)$ & $13(5.63)$ & $8(3.46)$ & $13(5.63)$ & $3(1.30)$ & $22(9.52)$ \\
\hline
\end{tabular}

Table 2: Frequency distribution of the studied sample according to their preferred time of studying the different medical education courses. 
Citation: Gouda EM, Youssef WT, Hamam AM, Fawzy MS (2013) Needs Assessment of the Undergraduate Medical Students to Incorporate Courses on Medical Education into the Undergraduate Curriculum at the Faculty of Medicine, Suez Canal University. Intel Prop Rights 2: 109. doi:10.4172/2375-4516.1000109

Seventy six percent of the students who participated in the current study indicated that they preferred to study the principles of PBL and $(95 \%)$ of them declared that they want to study it in the first year. This finding matches the research of Caplow [12] who found that the students expressed interest towards PBL and also with Schmidt [13] who found that the students seem to have difficulty in adjusting to PBL that result in considerable stress so they sought guidance in the first year. This in accordance with the logic thinking as the students face difficulty in the first year due to the sudden shift from the traditionally secondary schools to an innovative problem based learning schools.

One of the limitations of the current study was the absence of suggesting some important topics such as professionalism and leadership and management. Since these topics are globally introduced in the undergraduate health profession education, their consideration in the future is highly recommended.

It is worth to mention also that some suggested topics were already taught in the introductory block in the first year in FOM-SCU for example; the principles of PBL, COME and group dynamics. Block reform according to learners' needs is also recommended.

\section{Conclusion}

It is important for undergraduate students to acquire knowledge, skills, and attitudes concerning their learning processes and some of the principles of medical education, especially in a faculty that adopts innovative educational strategies like FOM-SCU. It showed that the students themselves were interested in receiving these principles.

\section{References}

1. Amin Z (2004) Medical Education in Asia. Annals Academy in Medicine 33 264-266.
2. Davis $\mathrm{MH}$, Karunathilake I, Harden RM (2005) The Development and Role of Departments of Medical Education. Med Teach 27: 665-675.

3. Harden RM (2000) Evolution or Revolution and The Future of Medical Education: Replacing The Oak Tree. Med Teach 22: 435-442.

4. O'Connell MT, Pascoe JM (2004) Undergraduate Medical Education for the 21st Century: Leadership and Teamwork. Fam Med 36: S51-S56.

5. Kern DE, Thomas PA, Howard DM, Bass EB (1998) Curriculum Development for Medical Education. A Six Step Approach. In; Needs Assessment of Targeted Learners. Baltimore: Maryland. Editors: Kern DE, Thomas PA, Howard DM, Bass EB.

6. Whittle SR, Eaton DG (2001) Attitudes Towards Trasferable Skills in Medical Undergraduates. Med Educ 35: 148-153.

7. Sleight $P$ (1995) Teaching Communication Skills: Part of Medical Education? J Hum Hypertens 9: 67-69.

8. Cuff PA, Vanselow N (2004) Improving Medical Education: Enhancing The Behavioral And Social Science Content of Medical School Curricula. National Academies Press, USA.

9. Figueroa DE (1989) Medical Ethics Education in the Eighties: A Study of Five Medical Schools. Med Teach 11: 177-185.

10. Adamson BJ, Covic T, Lincoln M (2004) Teaching Time And Organizational Management Skills To First Year Health Science Students: Does Training Make A Difference? Journal of Further and Higher Education 28 : 261-276.

11. Goldie J, Schwartz L, Morrison J (2000) A Process Evaluation of Medical Ethics Education in the First Year of A New Medical Curriculum. Med Educ 34: 468473.

12. Caplow JA, Donaldson JF, Kardash C, Hosokawa M (1997) Learning In A Problem-Based Medical Curriculum: Students' Conceptions. Med Educ 31: 440-447.

13. Schmidt HG, Van Der Arend A, Moust JHC, Kokx I, Boon L (1993) Influence Of Tutors' Subject-Matter Expertise On Student Effort and Achievement in Problem-Based Learning. Acad Med 68:784-791. 